\title{
Declaración y llamada de acción de la FITS LAC - Federação Internacional de Assistentes Sociais*
}

La Federación Internacional de Trabajo Social para América Latina e o Caribe está composta por organizações siguientes em 17 países: Federación Argentina de Asociaciones Profesionales de Servicio Social; Consejo Federal de Servicio Social de Brasil; Colegio de Trabajadores Sociales de Chile; Colegio de Trabajadores Sociales de Costa Rica; Asociación de Asistentes Sociales del Uruguay; Colegio de Profesionales del Trabajo Social de Puerto Rico; Federación Colombiana de Trabajadores Sociales; Asociación Nicaragüense de Trabajadores Sociales "Mildred Abauza"; Asociación Dominicana de Profesionales del Trabajo Social; Asociación Haitiana de Trabajadores Sociales; Associação de Trabalhadores Sociais Profissionais de Grenada; Asociación de Trabajadores y Trabajadoras Sociales de El Salvador; Asociación de Trabajadores Sociales de Panamá;

Estas organizaciones reconocemos que o COVID-19 é a crise sanitária e social mais grande que está experimentado neste siglo con enormes e peligrosas repercusiones para a vida, proteção e exercício efetivo dos derechos de nuestros pueblos. siguiente:

En el marco desta pandemia mundial declaramos y afirmamos lo

1. La mayoría de los países del mundo han impuesto medidas de aislamiento físico para evitar la propagación de la enfermedad. Dentro de esas medidas se ha restringido o libre movimiento de las personas ciudadanas y se han ordenado toques de queda ou limitaciones para salir de los hogares.

2. Aunque reconocemos que algunas de estas medidas son necesarias, como profesionales del trabajo y servicio social no podemos dejar de expresar las serias consecuencias sociales que tienen estas medidas.

3. As restrições impuestas han provocado que muchas personas pierdan sus trabajos, importantes pérdidas de ingresos e situações que afetam a saúde vivienda educação alimentação e proteção social de los setores empobrecidos e em exclusão social Las medidas también han agravado la

\footnotetext{
* Nota-manifesto publicada originalmente, em 13 de abril de 2020, pela Federação Internacional de Assistentes Sociais em seu site (https://www.ifsw.org/declaracion-y-Ilamado-de-accion-de-la-fits-lac/) e autorizada a republicação nesta edição da Revista Em Pauta: teoria social e realidade contemporânea pela vice-presidente da Instituição, Tânia Godoi Diniz, a quem estendemos nossos agradecimentos. Copyright $\odot 2020$ Federação Internacional de Asssistentes Sociais Endereço registrado: Maiengässli 4, 4310 Rheinfelden, Suíça. Número registrado da instituição de caridade: CHE-109.240.290
} 


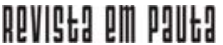

\} DECLARACIÓN Y LLAMADA DE ACCIÓN - FITS \}

DOI: $10.12957 /$ REP.2021.60308

ya precaria situación de las personas that viven de sus trabajos. En estos tempos de urgência e emergência são apresentados um abanico cada vez mais amplio de categorias para tipos de contratos e jornadas laborales que desestabilizam as condições de vida da clase trabajadora. El trabajo social se vuelve parte constitutivas de las contradicciones del modelo inclusivo. Su devenir está atravesado de forma directa y violenta por las condiciones de precarización laboral, que nenhum solo limitan su accionar,

4. La situación de confinamiento en el hogar exacerba problemáticas como la violencia basada en género y generaciones (niñez, adultos mayores) y los abusos sexuais. A investigação estabelece que a vulnerabilidade e os peligros de daño para estas poblaciones aumenta porque o espaço de la vivienda invisibiliza a estas personas en los contextos públicos donde pueden ser visibilizadas y protegidas. De igual forma, están expuestas a sus agresores en tiempo, espacio y oportunidad.

5. La situación de vulnerabilidad de las poblaciones migrantes se precariza en estos contextos. Muchos de ellos por su situación migratoria carecen de acceso a los sistemas de prestaciones sociales, educación y salud. Em todos os países, a situação de emergência do COVID-19 foi usada como desculpa para recrudecer os malos tratos e a violação de derechos para esta población.

6. Algunos países com sistemas de saúde privatizados carecen de procesos de prestación de servicios universales y durante a pandemia han aflorado situaciones severas de acceso a hospitais, médicos, laboratorios, farmacias y otros de servicios de salud física y mental. En otros países hay escases de pruebas, equipos de assistencia respiratoria, dilatación de resultados y problemas para recopilar estadísticas y realizar proyecciones epidemiológicas que son vitales to la respuesta a esta pandemia mundial.

7. Se ha reportado escasez de material de limpeza necesario para las medidas de prevención de contagios.

8. Carencia de atención a grupos con necesidades especiales que incluyen, pero no se limitan a las personas sin vivienda, groups con diversidades funcionais, comunidades aisladas o colectivos que dependen de ingresos diarios. Estos grupos requieren medidas especiais para atenderles, tener acceso a prestaciones sociales, información, servicios de salud y otras medidas para resolver las situaciones de vida particulares.

9. Un aumento en la tensión hacia las personas, familias, comunidades y organizaciones producto de los estresores que provoca la enfermedad y las medidas necesarias para combatirla. Para muchas personas, estas tensões aumentan su vulnerabilidade para o desarrollo de condiciones emocionales o que se exacerben condiciones que ya existen. Isso inclui as tensões de las personas que trabajan a distancia, la educación de las hijas e hijos en el hogar y la falta de acceso a equipos tecnológicos, internet y otro equipo de comunicación necesario para el acceso a la información, educación a distancia y la tramitación de ayuda durante a pandemia. Se añaden 


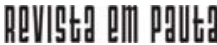

\} DECLARACIÓN Y LLAMADA DE ACCIÓN - FITS \}

DOI: 10.12957/REP.2021.60308

las tensiones productos del miedo al contagio, el aumento de problemas de saúde mental.

10. Em todos os países, se reporta um aumento na corrupção política para o manejo de emergência e o desvio de fundos para favorecer a corporações e personas afines com as elites políticas.

11. Muitos lugares relatam serviços deficientes de comunicação pública e falta de sincronização na respuesta del Gobierno. Esto provoca que from las mismas estructuras políticas se brinden mensajes contradictorios y se genere tensión y desesperanza en las personas.

12. Em outros países, há primado la atención de salud de una forma desarticulada de la prestación de servicios sociales. En esas respuestas se olvida que a calidad de la salud en los países está especificada por otros fatores sociais que tienen que atenderse durante cualquier respuesta salubrista. Observamos com preocupação como las personas profesionales del trabajo social y otras profesiones relacionadas y necesarias a la respuesta de salud, son invisibilizadas and ignoradas en los incentivos gubernamentales dirigidos a la clase trabajadora en la respuesta de emergencia. Em muitos de nossos países las personas profesionales del trabajo social y otros profesionales de respuesta de emergencia carecen de protocolos y garantías de seguridadpara protegerse del contagio.

13. Alertamos sobre o aprovechamiento económico que están haciendo em particular as empresas que venden productos o servicios en el area salud (como con el cobro de pruebas o el álcool em gel, por ejemplo) assim como en geral el aumento de todos os produtos de consumo básico, lo cual empeora la situación de quienes menos tienen.

14. Muchas medidas de ayuda e resgatadas durante a pandemia de dirigidas nos grupos que nunca foram beneficiadas pelo poder e não abordadas nas verdaderas necesidades de las personas trabajadoras e grupos que históricamente foram excluidos e empobrecidas. Algunos países no marco da emergência han criar medidas de apoyo económico para a alimentação de famílias na situação de pobreza, pero a modalidad de ponerlas en vigor no ha sido planificada. A consumação de está ocorrendo foi que os setores importantes queden excluidos da ayuda e em outros casos, que a población se exponga à la propagación del contagio.

A base de estas situaciones reportadas por nuestras organizaciones and ident at el seguimiento que se la ha dado a la respuesta a esta pandemia a lo largo de América Latina y el Caribe, nuestros 17 países y organizaciones que representam a cientos de miles de profesionales del trabajo social en nuestra región reclamamos que los gobiernos de nuestros países:

1. Garanticen el acceso universal a la salud de todas as personas. Isso inclui a detecção e atenção à condição com independência de capacidade paga. Se requiere acciones para ampliar de forma inmediata la capacidad para hacer pruebas y seguimiento epidemiológico. Este, com atenção especial às zonas com os altos da Federação Internacional de Trabalho da 


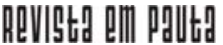

\} DECLARACIÓN Y LLAMADA DE ACCIÓN - FITS \}

DOI: $10.12957 /$ REP.2021.60308

Região Social da América Latina e do Caribe 4 enfermedad. En los países não existem sistemas universais de prestación de servicios, se insta a estabelecer leyes y reglamentos que exijan la atención de las personas en cualquier centre. La salud tiene que conceptuarse y garantizarse como un derecho y no puede estar al arbitrio de las corporaciones privadas que han hecho de la salud un negocio.

2. Reconozcan que la respuesta social esencial e indispensable para enfrentar la emergencia de salud y, por consiguiente, los servicios sociales tienen que articularse y formar parte de la respuesta de salud. Para esto, es necesario incorporar los grupos sociales, las agencias públicas que prestan servicios sociales, las comunidades y las profesiones relacionadas a la respuesta de salud física, mental y social. En esto, la presencia de las profesionales del trabajo social es indispensable en la generación, analogisis, implementación y avaliaación de políticas sociales dirigidas a enfrentar la pandemia. Se incluyen como necesarias las acciones profesionales sensibles a los contextos locales. Esto,

3. Se garantice un ingreso universal básico que no se limite al seguro por desempleo y que cubra las necesidades de las personas y familias durante la emergencia. En esto, es necesario la revisión y reforma de leyes laborales, la promulgación de leyes de protección a las personas desempleadas, a las personas que nenhum filho depende e viven de seu trabalho e o cuidado de las personas que tienen que laborar from sus hogares. Se debe enfatizar que não se pierdan las garantías y derechos laborales adquiridos. Los estados deben permanecerá vigilantes para que as empresas no tomen medidas que perjudiquen a sus empleados, ni ahora ni no futuro. Se deve velar por las garantías de cuidado a la población trabajadora de mujeres embarazadas, os adultos mayores y con diversidad funcional.

4. Desarrollen acciones prioritarias centradas en los grupos que historicamente han sido excluidos y en situación de desigualdad. Sobre este particular, se tiene que garantizar la atención a la niñez y juventud, mujeres, personas adultas mayores, setor empobrecidos, población inmigrante, personas sin hogar, colectivo LGBTQI, comunidades aisladas, población, población, de proteção penal e víctimas de sobreviventes. Esto incluye la garantía de acceso a transferencias electrónicas, los servicios de salud, medicamentos, servicios sociales, alimentación, despacho de medicamentos y alimentos en los hogares de grupos vulnerables al contagio, servicios de protección a las víctimas y sobrevivientes de agresión en relaciones de pareja, abuso sexual e delitos. En estas acciones el Estado está obrigado a velar que las restrciones sean las necesarias y que los derechos humanos sean garantizados à la vez que se lucha contra la enfermedad. Se insta a crear observatorios, aplicaciones de ayuda y respuesta rápida. De igual forma, se debe identificar os grupos e personas que necesitarán ser abordadas from sus contextos de vida, dotando a las profesionales de las condiciones de bioseguridad necesarias en el marco de la pandemia. 


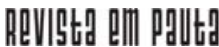

\} DECLARACIÓN Y LLAMADA DE ACCIÓN - FITS \}

DOI: $10.12957 /$ REP.2021.60308

5. Aseguren medidas que protegem a las familias y personas de acciones desahucio, desalojo, pérdida de transporte, embargos y acciones de cobro de dinero por parte de bancos e agencias de crédito.

6 . Incluir a las poblaciones migrantes en todos los servicios y garantizar los servicios esenciales para esta población con independencia de su estatus migratorio.

7. Garanticen and den acceso free to the población to los systems of telecomunicaciones that son indispensables to mantener had to the población on la enfermedad, la educación to the protección del contagio y la socialización of servicios disponibles.

8. Brinden la comunicación relacionada a la pandemia para brindar datos confiables evitando la incertidumbre e las reacciones de estampida que puedan exponer a las personas a contagio.

9. Garanticen el acceso de la población a mascarillas, equipo de seguridad y limpieza, al agua y la energía. Estas medidas deben ir acompañadas de um componente de educação sócio salubrista dirigido a evitar contágios ya la prevenção de problemas que se generan por las medidas de contención.

10. Identifiquen y utilicen actores sociales que incluyan gremios profesionales para estabelecer equipos de respuesta y atención garantizing la seguridad de las personas que trabajen en la respuesta rápida. Os equipamentos de respuesta de saúde ou de medidas econômicas desde os Estados deben trabajar en coordinación con los equipamentos de servicios sociaises. La integración de estas respuestas es indispensável. La falta de integración agravará los contagios y las problemáticas sociales that surgen como consecuencia de las medidas de contención de la enfermedad.

11. Mantengan la transparencia, integridad y rendición de cuentas en las acciones públicas para evitar que los recursos del Estado sean desviados hacia actividades corruptas.

12. Asseguren el acceso a servicios de salud mental y se trabaje con campañas dirigidas a la prevención y enfrentamiento de los estresores sociales que provocan tensión emocional.

13. Asignen recursos a los municipios, provincias, sector y organizaciones de atención social. Inclui a utilização de recurso humano que não está trabalhando de forma presencial em sus empleos e que está capacitado e con las cualificaciones profesionales necesarias para brindar consejería, hacer estudios de necesidades e realizar intervenciones Federación Internacional de Trabajo Social Región de América Latina y el Caribe 6 em crise e socioeducativas. Para esto, se recomienda la creación expedita de aplicaciones de transferencia de llamada o comunicación electrónica para usar este recurso humano em la respuesta con un enfoque social salubrista. Esto, considerando las necesidades de estos profesionales y compensándolos por el trabajo que realizan. 
Pongan en vigor la fijación estatal de precios al valor en el que estaban todos los productos al momento de comenzar la emergencia por la pandemia. Esto, tanto en los precios vinculados a la salud como en aquellos de alimentación and higiene.

Fortalezcan y brinden recursos a las universidades para desarrollar acciones, investigaciones y respuestas de salud, econômicas y sociales para el beneficio de toda la población.

Garanticen condiciones de trabalho de segurança para as pessoas profissionais do trabalho social, aquellas profesiones que têm que trabalhar na resposta à pandemia e outras pessoas que não pueden permaneceram em sus hogares. Esto incluye visibilizar los aportes e identidades de la profesión del trabajo social en los equipos de salud física y mental. Se añade la necesidad de brindar apoyo psicosocial a las profesionales de ayuda y un monitoreo constante de su salud. Todas las profesiones necesarias para la respuesta a la enfermedad deben ser compensadas y se deben desarrollar incentivos que ayuden a palear las condiciones de trabajo adversas.

Finalmente, hacemos un Ilamado a todos los gremios y académicos de trabajo social en América Latina y el Caribe para que se unam a acciones de respuesta y sirvan de garantes del respeto a los derechos de las poblaciones y de las profesionales del trabajo social. Es necesario que mantengamos la militancia en estos times de crise mundial para que as acciones de respuesta no sean excusa para restringir y violentar derechos. El grado de complejidad que adquieren hoy los escenarios de intervención profesional, nos plantean la necesidad de ampliar los paradigmas from donde se referencia el conocimiento, emplear teorías interpretativas del sujeto en sociedad articulado e interdependiente partiendo de su propia mirada, es decir reflexionar el de los modelos de intervención que estamos implementando. Dar o salto cualitativo que requer atuar simultaneamente, nas dimensões individuais e coletivas do sujeto e nos contextos e dimensões donde este se desenvuelve, pero comprendiendo también que son los nuestros. Lejos de coartar derechos, vivimos en tiempos donde el activismo para la defensa, exigibilidad y expansión de los derechos humanos es más necesario que en cualquier otro moment.

Larry Emil Alicea Rodríguez, MTS, JD - Presidente FITS ALC Dra. Tânia Maria Ramos de Godoi Diniz - Vice-presidente FITS ALC

Copyright $\odot 2020$ Federação Internacional de Assistentes Sociais Endereço registrado: Maiengässli 4, 4310 Rheinfelden, Suíça. Número registrado da instituição de caridade: $\mathrm{CHE}-109.240 .290$

DOI: $10.12957 /$ rep.2021.60308

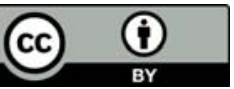

A Revista Em Pauta: Teoria Social e Realidade Contemporânea está licenciada com uma Licença Creative Commons Atribuição 4.0 Internacional. 